\title{
Sugar-sweetened carbonated beverage consumption correlates with BMl, waist circumference, and poor dietary choices in school children
}

Kate S Collison ${ }^{1 *}$, Marya Z Zaidi ${ }^{1}$, Shazia N Subhani ${ }^{2}$, Khalid Al-Rubeaan ${ }^{3}$, Mohammed Shoukri ${ }^{2}$, Futwan A Al-Mohanna'

\begin{abstract}
Background: The prevalence of obesity and overweight is increasing globally. Frequently coexisting with undernutrition in developing countries, obesity is a major contributor to chronic disease, and will become a serious healthcare burden especially in countries with a larger percentage of youthful population. 35\% of the population of Saudi Arabia are under the age of 16, and adult dietary preferences are often established during early childhood years. Our objective was to examine the dietary habits in relation to body-mass-index (BMI) and waist circumference (W_C), together with exercise and sleep patterns in a cohort of male and female Saudi school children, in order to ascertain whether dietary patterns are associated with obesity phenotypes in this population.

Methods: 5033 boys and 4400 girls aged 10 to 19 years old participated in a designed Food Frequency Questionnaire. BMI and W_C measurements were obtained and correlated with dietary intake.

Results: The overall prevalence of overweight and obesity was $12.2 \%$ and $27.0 \%$ respectively, with boys having higher obesity rates than girls $(P \leq 0.001)$. W_C and BMI was positively correlated with sugar-sweetened carbonated beverage (SSCB) intake in boys only. The association between male BMI and SSCB consumption was significant in a multivariate regression model $(P<0.0001)$. SSCB intake was positively associated with poor dietary choices in both males and females. Fast food meal intake, savory snacks, iced desserts and total sugar consumption correlated with SSCB intake in both boys $(r=0.39,0.13,0.10$ and 0.52 respectively, $P<0.001)$ and girls $(r=0.45,0.23,0.16$ and 0.55 respectively, $P<0.001)$. Older children reported eating significantly less fruit and vegetables than younger children; and less eggs, fish and cereals. Conversely, consumption of SSCB and sugarsweetened hot beverages were higher in older versus younger children $(P<0.001)$. BMI and $W \_C$ were negatively correlated with hours of night-time sleep and exercise in boys, but only with night time sleep in girls, who also showed the lowest frequency of exercise.
\end{abstract}

Conclusions: A higher intake of SSCB is associated with poor dietary choices. Male SSCB intake correlates with a higher W_C and BMI. Limiting exposure to SSCB could therefore have a large public health impact.

\footnotetext{
* Correspondence: kate@kfshrc.edu.sa

${ }^{1}$ Cell Biology \& Diabetes Research Unit, Department of Biological \& Medical Research, King Faisal Specialist Hospital \& Research Centre, PO BOX 3354, Riyadh 11211, Saudi Arabia
} 


\section{Background}

The prevalence of overweight and obesity amongst children in Saudi Arabia has previously been reported to be between $8-14 \%$ and $6-17 \%$ respectively [1,2]. Several studies suggest that these levels are rising alarmingly [3,4]. Obesity is a risk factor for cardiovascular disease [5], Diabetes [6] and certain types of cancer [7]. It can also be associated with non-fatal but debilitating illnesses such as respiratory difficulties, infertility and musculoskeletal disorders [8]. Additionally, increased waist circumference (W_C) has been associated with the risk of developing Insulin Resistance [9] and Metabolic Syndrome [10]. Several recent studies suggest that increased abdominal adiposity and $\mathrm{W}_{-} \mathrm{C}$ is a strong predictor of all-cause mortality $[11,12]$. Worldwide obesity has increased dramatically, and in the last two decades this condition which was once considered primarily a disease of industrialized countries, now increasingly affects individuals from developing countries at even higher growth rates $[13,14]$. According to data available in 2004 from the WHO Global Database on Body Mass Index, the adult prevalence of overweight in Saudi Arabia was $72.5 \%$ in the population aged between 30 and 70 years [15]. Additionally, $35 \%$ of the Saudi population are under the age of 16 , compared to $20 \%$ in the United States, and thus the burden of healthcare is likely to increase considerably in the next several decades. Childhood corpulence is a predictor for adult disease $[8,16]$. In particular, recent studies have shown that increased BMI in childhood may predict the occurrence of obesity in adulthood $[17,18]$. Since the prevalence of obesity amongst the existing adult Saudi population is already high $[19,20]$, and in view of the poor success rate of adult obesity treatment programs [21], there is a growing need to develop preventive strategies aimed towards the younger population. In children as opposed to adults, the BMI values vary with both age and gender, thus the preferred assessment is BMI-for-age, in which children with a BMI-for-age between the $85^{\text {th }}$ and $95^{\text {th }}$ percentile are classified as being overweight and those in the $\geq 95^{\text {th }}$ percentile are considered obese [22].

Excessive calorie intake in the form of a number of macronutrients has been associated with weight gain. Energy intake from sugar-sweetened carbonated beverages (SSCB) now accounts for a significant fraction of the total caloric intake of young people [23], and consumption has been implicated in promoting obesity in several [24-27], but not all studies [28-31]. Sucrose, fructose and glucose-sweetened beverage intake has been associated with poor diet quality [31,32] and fast food consumption [33]. Although SSCB intake has increased dramatically over the past several decades [34], the effect on health outcome associated with SSCB intake is still the subject of much debate [35]. Out of 25 individual cross-sectional and prospective cohort studies, only 12 have identified significant associations between soft drink consumption and weight gain [35]. SSCB intake has also been associated with hypertension and dyslipidemia [36], components which together with increased adiposity constitute the Metabolic Syndrome, a common for-runner of Type 2 Diabetes. Recent studies indicate that the prevalence of adult obesity, diabetes and the Metabolic Syndrome is increasing in Saudi Arabia [19,20,37,38], in line with other developing countries world-wide.

Given these observations, the influence of SSCB on diet quality can be viewed as a worldwide health concern. The aims of this study were to examine the dietary patterns that may affect anthropological factors of male and female Saudi school students between the age of 10 and 19, and to determine the prevalence of any nutritional trends which may impact on health outcomes in the future. A designed questionnaire was used to collect data regarding dietary habits, weight, height, BMI, waist circumference, physical activity and sleep patterns.

\section{Methods}

\section{Subjects and survey procedure}

This was a cross-sectional study conducted during the scholastic year of 2007, which included both male and female Saudi children between the ages of 10 and 19, randomly selected from 450 intermediate and secondary schools in different regions of the capital city of Riyadh, corresponding to $2.7 \%$ of the Riyadh student population for that year. The study protocol was reviewed and approved by the Institutional Review Board (IRB) and because all data were collected anonymously, a waiver of consent was granted by the Research Ethics Committee of the King Faisal Specialist Hospital \& Research Centre. Parents were notified in writing about the objectives of the study and were invited to contact their respective schools to ask questions or to withdraw their child from the study. A total of 10,000 subjects were interviewed, and after removing subjects with missing/ incomplete data, 9433 anonymized entries were included in the study, aged between 10 and 19 years, with an overall male to female ratio of 1.14. Anthropometric measurements of weight, height and waist circumference were carried out by the same team of experienced nurses and one attending physician in order to avoid inter-examiner variability. Weight was measured in light clothing and without shoes using a digital scale, and was recorded to the nearest $100 \mathrm{~g}$. Height was measured as the distance from the top of the head to the bottom of the feet without shoes using a fixed stadiometer. BMIfor-age (calculated as $\mathrm{Kg}$ body weight $/ \mathrm{m}^{2}$ ) was 
categorized as $<5^{\text {th }}$ percentile, $\geq 5^{\text {th }}$ and $<85^{\text {th }}$ percentile, $\geq 85^{\text {th }}$ and $<95^{\text {th }}$ percentile, and $\geq 95^{\text {th }}$ percentile using 2000 Centre for Disease Control gender-specific growth charts [22]. Waist circumference was measured at the narrowest part between the lower rib and the iliac crest (the natural waist) using a non-elastic flexible tape and recorded to the nearest $0.1 \mathrm{~cm}$. Age and genderspecific W_Cs were divided into the following percentiles according to Fernandez et al [39]: $\leq 10^{\text {th }}$ percentile; $\geq 10^{\text {th }}$ and $\leq 75^{\text {th }}$ percentile; $\geq 75^{\text {th }}$ and $\leq 90^{\text {th }}$ percentile and $\geq 90^{\text {th }}$ percentile.

\section{Dietary assessment}

A purpose-designed 7-day food frequency questionnaire (FFQ), previously translated into Arabic and including colored pictures of the food items under investigation was used in this study. Children were briefed as to how to complete the questionnaire prior to filling out their response. The variables studied were related to 7-day recall of intake of several types of commonly available fast food meals such as beef burger meal with French fries and a choice of either sugar-sweetened or diet carbonated beverage, chicken burger meal, chicken nugget meal or fried chicken meal. Other items such as apple pie, frozen desserts and pizza were included in the survey on the basis of their availability at fast food restaurants. Major nutrient sources queried included eggs, cheese, fish, selected fruits (apples, oranges bananas and dates) and vegetables (carrots, salad and corn), bread, sweetened and unsweetened cereal, sweet and savory snacks and drink consumption. Items included in the questionnaire were selected from a larger list of food and drink items, the frequency of consumption having previously been tested in a small pilot study performed with 420 Riyadh school children during the preceding scholastic year. The survey included questions related to SSCB intake either as part of a fast food meal, or alone. Other items included as independent variables based on their possible relationship with beverage intake were donuts, muffin/cake, ice cream, and savory snacks such as potato crisps and popcorn). Local foods were also featured in the questionnaire in the form of shawarma, and a typical rice and meat dish (Kabsa). For tea, coffee and milk, number of cups consumed per week were recorded. The number of spoonfuls of sugar added to beverages ( $5 \mathrm{~g}$ per serving) was also included in the questionnaire. The nutrient content of these food items was calculated from the USDA National Nutrient Database for Standard Reference [40] and verified wherever possible by nutritional information from food manufacturers.

\section{Physical activity and sleep patterns}

The frequency of physical activity was monitored. Students were asked to report the number of occasions per week that they took part in exercise consisting of 30 minutes or more of moderate activity. Students were also asked to record their normal duration of night-time and day-time sleep.

\section{Statistical Analysis}

Only forms with a complete set of valid data were included in this study, in which we aimed to sample 10,000 children. The response rate was $94.4 \%$, with the remaining subjects electing not to participate. All statistical analyses were performed using SPSS version 13.0 (SPSS, Inc., Chicago IL.). One way ANOVA with Tukey's posthoc test was used to compare differences in means of BMI, W_C, food intake frequency, exercise frequency and sleep patterns amongst gender within the three age groups $(n=9433)$. Percentage data were compared using the z-test for column proportions. Statistical significance was set at $\mathrm{P} \leq 0.05$ for all tests. For the correlation analysis, the data was filtered for possible over and under reporting by mean intake \pm 1 standard deviation [41] of mean total Kcal intake as recommended by Ventura et al [42]. Following this exclusion, 7031 $(74.5 \%)$ data entries were used in the correlational analyses. Pearson's correlations were calculated for males \& females separately to evaluate the association of anthropometric variables BMI \& W_C with self-reported food intake frequencies \& the nutrients calculated based on the intake. Spearman's correlations were calculated for the categorical variables of self-reported hours of nighttime and day-time sleep, and number of exercise occasions. Gender-specific Multiple Linear Regression analysis was applied for the determination of the best predictors among the self-reported dietary intake variables, sleep and exercise patterns of BMI and W_C. Variables were subjected to bivariate analyses versus BMI or W_C. Those with a P-value of $<0.2$ were then entered in a Multiple Linear Regression model using the stepwise method. Results were reported for the final model as standardized beta coefficient ( $\beta$ ), level of statistical significance and $95 \%$ confidence intervals.

\section{Results}

The study sample consisted of 9433 male and female students divided into 3 age groups (10-13 yrs, 14-16 yrs, 17-19yrs), with a male: female ratio of 1.14 to 1 (Table 1). The overall prevalence of overweight children (BMI $\geq 85^{\text {th }}$ and $<95^{\text {th }}$ percentile) was $15.5 \%$, whereas obese (BMI $\geq 95^{\text {th }}$ percentile) children constituted $21.1 \%$ of the study population. Regardless of age or gender, approximately $55 \%$ of this population had a BMI-for-age within the normal range of between $\geq 5^{\text {th }}$ and $<85^{\text {th }}$ percentile. Male and female underweight $\left(\leq 5^{\text {th }}\right.$ BMIfor-age percentile) children accounted for $10 \%$ and $6.8 \%$ of the population respectively. Overweight children 
Table 1 Anthropometric characteristics of the subjects divided into tertiles by age

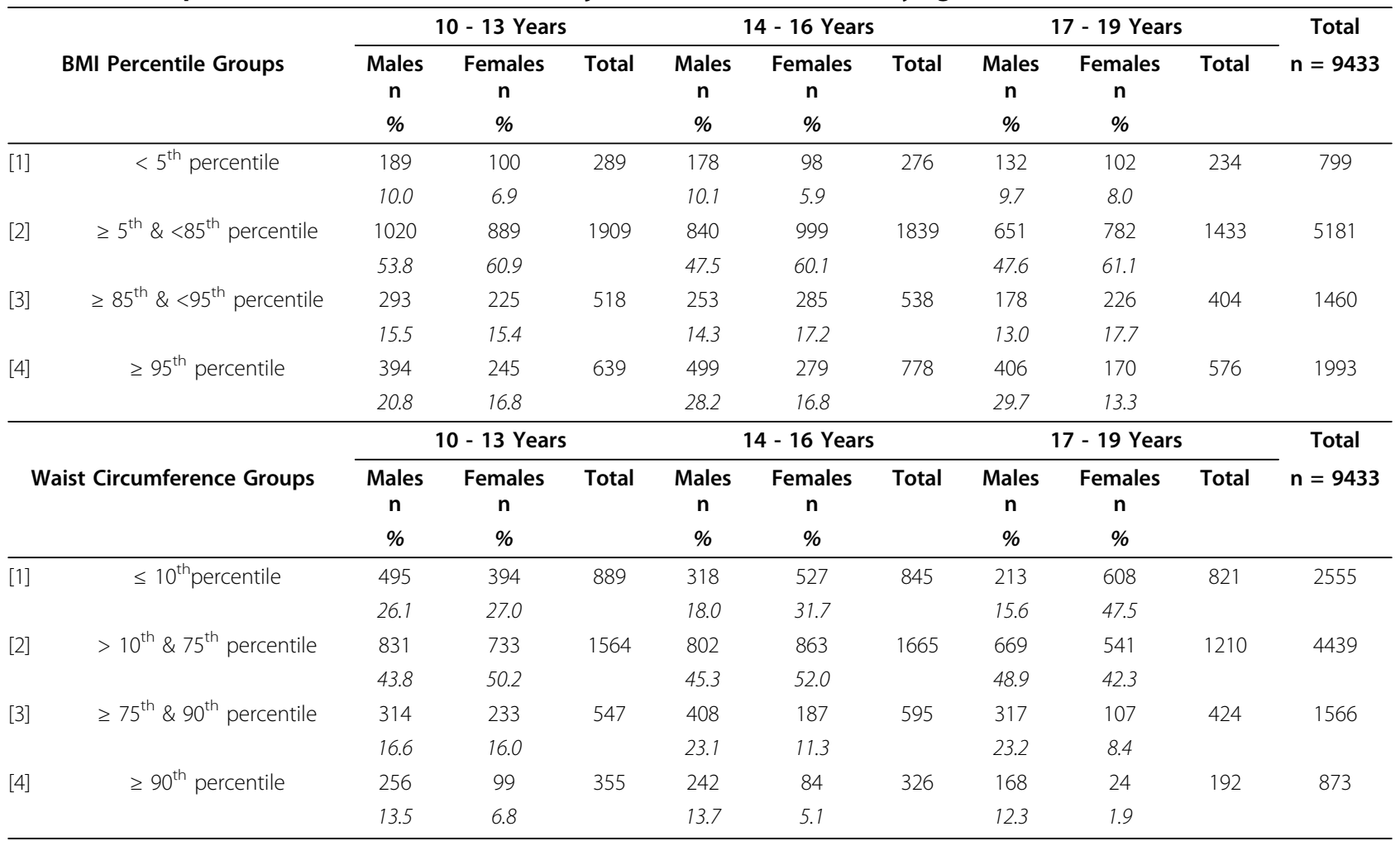

(between the $85^{\text {th }}$ and $95^{\text {th }}$ BMI-for-age percentile) accounted for $14.4 . \%$ of males and $16.7 \%$ of females, with the remainder ( $25.8 \%$ male and $15.7 \%$ female) having BMI-for-age values of $\geq 95^{\text {th }}$ percentile (Table 1 and Figure 1). There were significantly more boys achieving a BMI-for-age $\geq 95^{\text {th }}$ percentile than girls, indicating a higher prevalence of obesity amongst male students $(\mathrm{P}<$ 0.001). The numbers of obese male, but not female children also increased with age, so that there were higher numbers of obese children aged 16-19 years than at $10-13$ years $(\mathrm{P}<0.001)$. Waist Circumference $\left(\mathrm{W}_{-} \mathrm{C}\right)$ measurements showed similar gender differences, with a higher percentage of boys achieving $\mathrm{W}_{-} \mathrm{C}$ scores in the $\geq 90^{\text {th }}$ percentile compared to girls, regardless of age group (Table 1 and Figure 2, $\mathrm{P}<0.001$ ). A greater number of female students also had W_C measurements in the $\leq 10^{\text {th }}$ percentile range compared to males (Table 1 and Figure $2, \mathrm{P}<0.001)$.

The mean BMI, W_C and weekly intake of selected food items and macronutrients per age group for male and female children is shown in Table 2. Amongst the 9433 children surveyed, mean W_C significantly increased with age, with boys having larger W_C measurements than girls (Table $2, \mathrm{P}<0.001$ ). Mean BMI measurements were higher in boys versus girls only at age 17-19 $(\mathrm{P}<0.001)$. Sugar-sweetened carbonated beverage (SSCB) consumption varied from 5.93 to 9.04 servings a week, and was significantly higher than consumption of non-caloric sweetened "Diet" carbonated beverage (DCB), which varied between 0.92 and 1.52 servings per week (Table $2, \mathrm{P}<0.001$ ). Whereas there was no significant difference between the total Kcals from the self-reported variables consumed by children aged 10 to 19 , the reported frequency of weekly consumption of milk (both full fat and low fat), fruit, vegetables, fish, eggs and cereal, pizza, sweet snacks, ice cream and DCB decreased with advancing age in both genders (Table $2, \mathrm{P}<0.01$ ). Conversely, the frequency of reported consumption of SSBC, added sugar in hot beverages and total sugar intake increased with age in both males and females, suggesting a trend towards sugar-rich foods and away from healthier food choices with advancing age. Additionally, whereas boys consumed significantly more SSCB than girls, and also more DCB, full-fat milk, eggs, fruit, savory snacks and added sugar in hot beverages; boys did not report consuming more fruit juice, low-fat milk, vegetables, fish, cheese, bread, cereals, fast food meals, pizza, sweet snacks or ice cream than girls, regardless of age group.

Hours of both night-time and day-time sleep were surveyed, together with frequency of exercise occasions per week. The number of children reporting less than 6 hours of night-time sleep increased with advancing age, with a higher percentage of girls reportedly having 


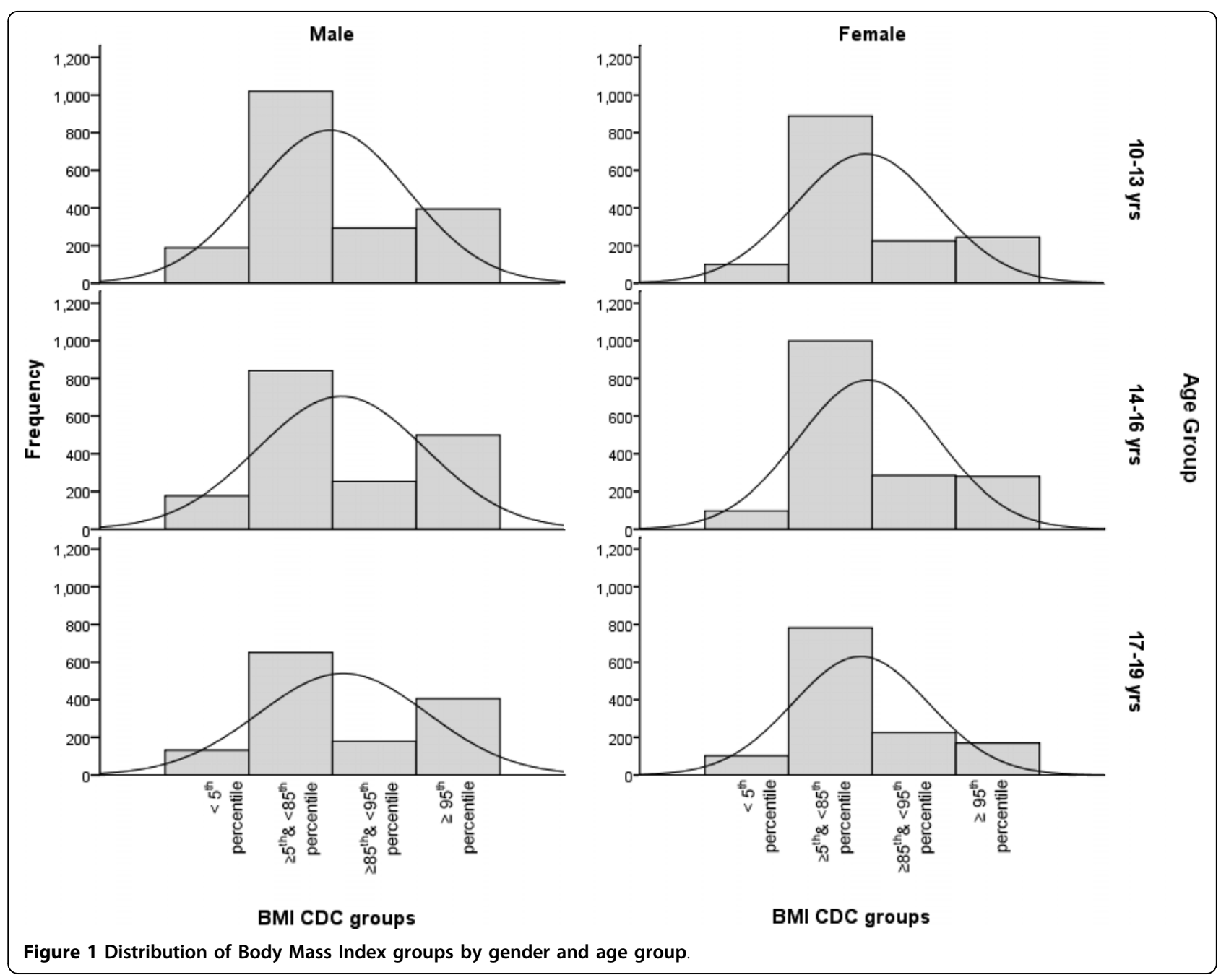

$<6$ hours sleep compared to boys of similar ages (Table $2, \mathrm{P}<0.05)$. Conversely, more girls reported sleeping for one or more hours during the day compared to boys $(\mathrm{P}<0.05)$. Frequency of exercise decreased with increasing age in both genders (Table $2, \mathrm{P}<0.001$ ). Additionally, boys exercised more than girls across all age groups, with up to $40 \%$ of girls reporting performing no exercise at all $(\mathrm{P}<0.05)$.

Table 3 shows SPSS output tables for Pearson $\mathrm{r}$ correlations among male and female BMI, W_C and selected food intake frequencies for each of 21 food items. In order to exclude potential over- and under-reporting, we used a \pm 1 standard deviation cut-off for the mean total Kcal intake as recommended by Ventura et al [37]. After this exclusion, a total of 7031 data entries $(74.5 \%$ of the total population) were subjected to correlation analysis, comprising of 3781 boys and 3250 girls. Of the data entries excluded from the correlation analysis, $11.1 \%$ of the survey population were found to be underreporters based on the \pm 1 SD cut-off values, and $14.4 \%$ were over-reporters. Correlation analysis of the main portion of our population indicated that waist circumference (W_C) and BMI were positively correlated with SSCB intake in boys but not girls $(r=0.10$ and 0.09 respectively, $\mathrm{P}<0.001)$. SSCB consumption was positively associated with poor dietary choices in both males and females. Fast food meal intake, savory snacks, iced desserts and sugar intake correlated with SSCB intake in both males $(\mathrm{r}=0.39,0.13,0.10$ and 0.52 respectively, $\mathrm{P}<0.001)$ and females $(\mathrm{r}=0.45,0.23,0.16$ and 0.55 respectively, $\mathrm{P}<0.001$ ). Full fat milk intake positively correlated with fruit, vegetable, eggs and cheese preferences in both boys $(r=0.20,0.14,0.17,0.14$ and 0.12 respectively, $\mathrm{P}<0.001)$ and girls $(\mathrm{r}=0.19,0.14,0.14$, 0.15 and 0.17 respectively, $\mathrm{P}<0.001)$. There was a negative correlation between W_C and full fat milk, fruit, vegetable and fish intake in males only $(r=-0.07,-0.1$, -0.09 and -0.07 respectively, $\mathrm{P}<0.001$ ).

Although both BMI and W_C were inversely correlated with frequency of exercise in males (Table 4, 


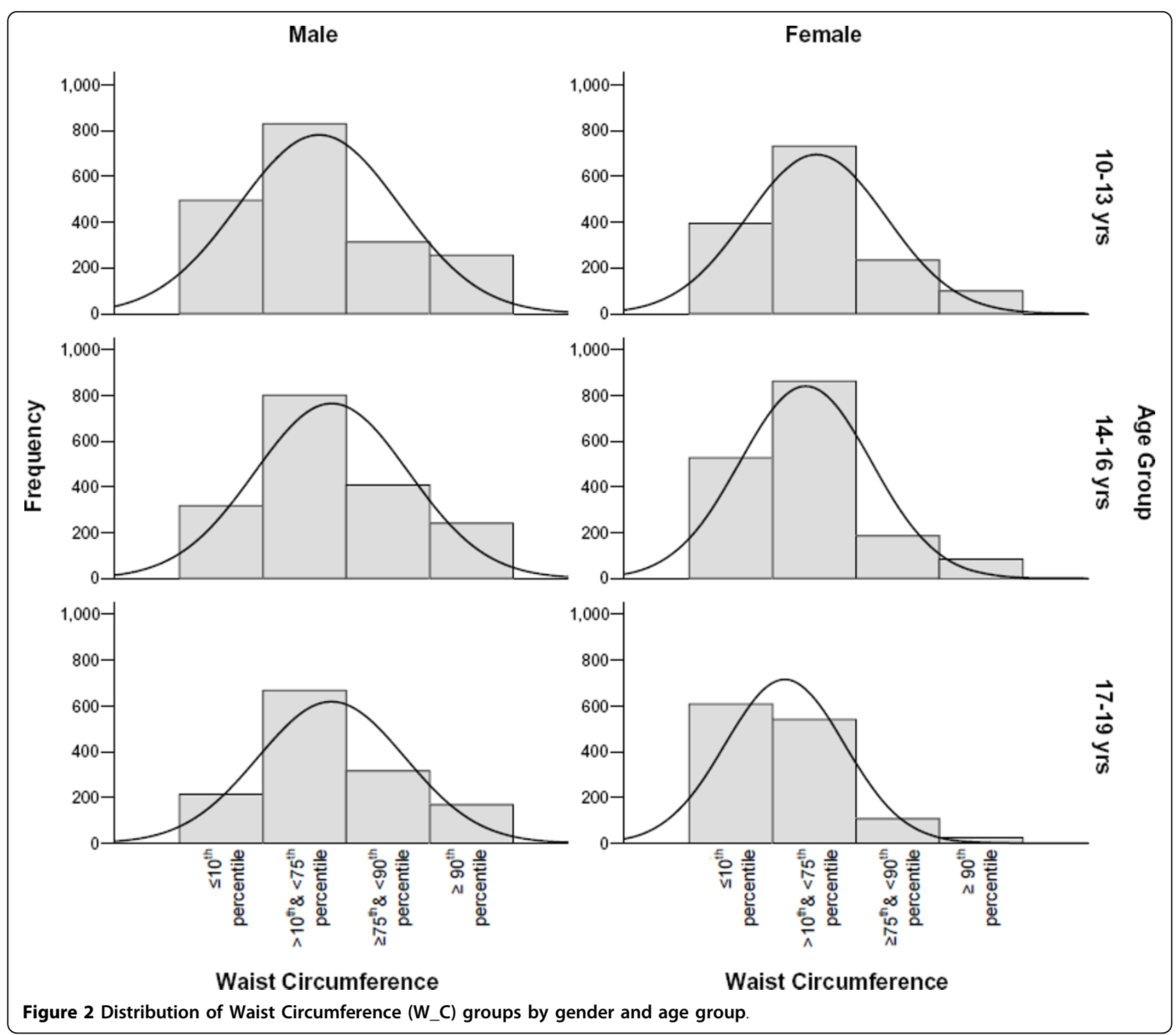

$P \leq 0.001$ ), this was not the case for females. However, exercise positively correlated with fruit, vegetable and unsweetened cereal intake in both genders, and also with full-fat milk intake in males only. Hours of nighttime sleep was negatively correlated with BMI and W_C in both boys and girls, whereas day-time sleep correlated positively with SSCB intake in boys and negatively correlated with SSCB in girls.

Table 5 shows the final multivariate regression model for the correlates of BMI in boys and in girls. BMI positively correlated with male SSCB consumption ( $\beta 0.10$, $\mathrm{P}<0.0001$ ), suggesting that every unit increase in selfreported SSCB consumption is associated with a $10 \%$ increase in BMI. BMI was also positively correlated with bread consumption in both genders, $(\mathrm{P} \leq 0.0001)$, and added sugars in beverages also had a significant positive association with BMI. In both genders, hours of night time sleep was negatively correlated with BMI, and in boys, BMI was negatively correlated with number of exercise occasions $(\mathrm{P} \leq 0.0001)$. Similarly, waist circumference was positively correlated with self-reported male SSCB intake in a multivariate regression model (Table 6, $\beta$ 0.10, $\mathrm{P}<0.0001)$.

\section{Discussion}

In this study we surveyed BMI, W_C, dietary habits and exercise/sleep patterns of a cohort of 9433 male and female Saudi school children aged 10-19, since many aspects of adult physical and nutritional behavior are often established during childhood and adolescence [43]. The overall prevalence of overweight children (BMI $\geq$ $85^{\text {th }}$ and $\leq 95^{\text {th }}$ percentile) was $15.5 \%$, whereas obese children constituted $21.0 \%$ of the population, which is higher than previous reports [1,2]. A significantly higher 
Table 2 Descriptive characteristics of self-reported weekly food intake, exercise and sleep patterns in males and females; $n=5033,4400$ respectively

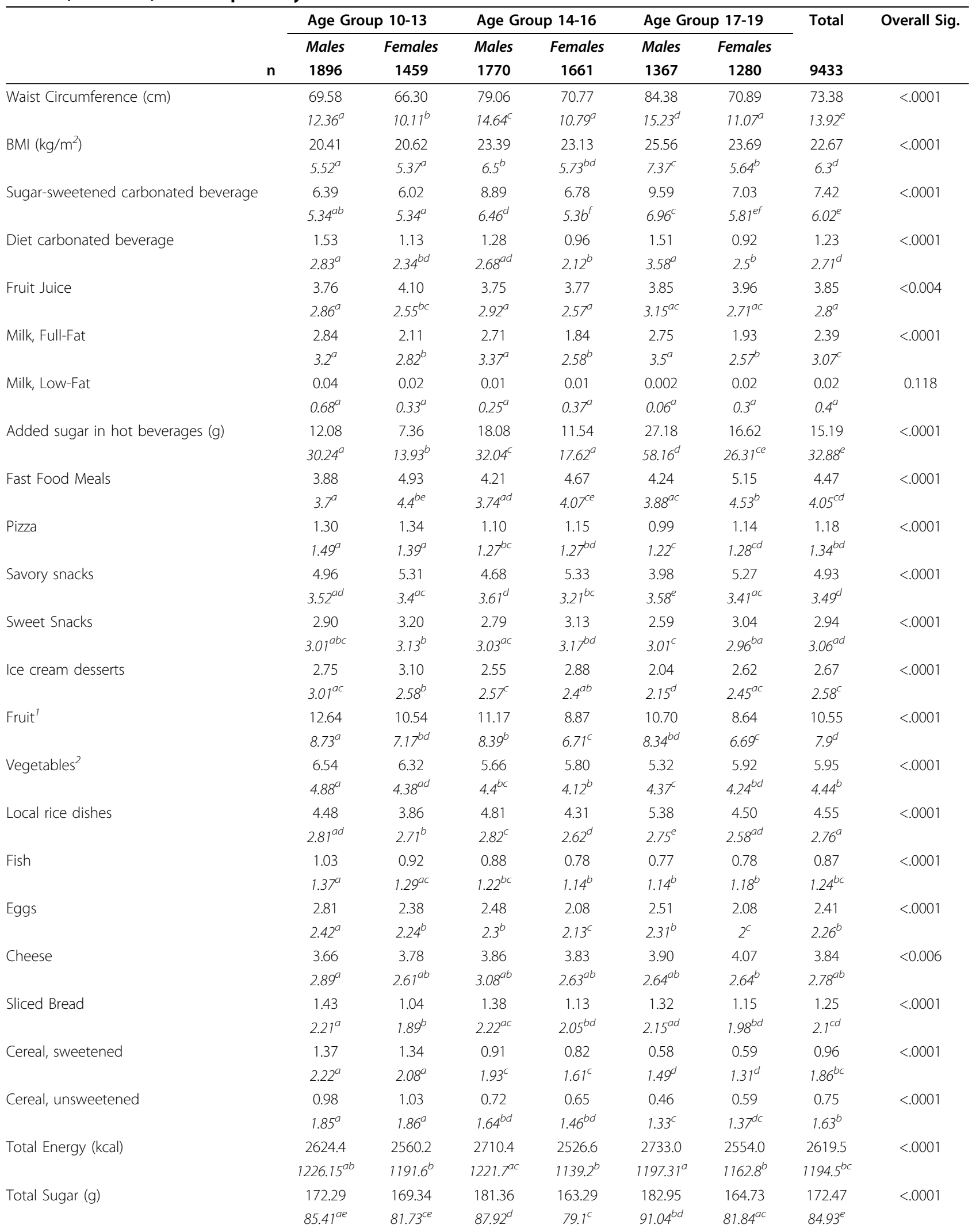


Table 2: Descriptive characteristics of self-reported weekly food intake, exercise and sleep patterns in males and females; $\mathbf{n}=\mathbf{5 0 3 3}, \mathbf{4 4 0 0}$ respectively (Continued)

\begin{tabular}{|c|c|c|c|c|c|c|c|c|}
\hline \multirow[t]{2}{*}{ Total Fat (g) } & 102.95 & 102.29 & 105.76 & 102.01 & 105.90 & 103.17 & 103.67 & 0.157 \\
\hline & $51.08^{a}$ & $50.11^{a}$ & $50.7^{a}$ & $48.67^{a}$ & $48.75^{a}$ & $49.41^{a}$ & $49.89^{a}$ & \\
\hline Total Saturated Fat (g) & 34.72 & 34.81 & 35.06 & 34.17 & 34.50 & 34.14 & 34.59 & 0.695 \\
\hline \multirow[t]{2}{*}{ Number of exercise occasions } & 2.36 & 1.09 & 2.05 & 0.89 & 1.71 & 0.75 & 1.54 & $<.0001$ \\
\hline & $1.85^{a}$ & $1.35^{b}$ & $1.81^{c}$ & $1.18^{d}$ & $1.71^{e}$ & $1.1^{d}$ & $1.67^{9}$ & \\
\hline \multirow[t]{2}{*}{ Children performing no exercise $^{3}$} & 254 & 486 & 301 & 662 & 317 & 611 & 2,631 & $<0.05$ \\
\hline & $(13.4)^{\mathrm{a}}$ & $(33.3)^{b}$ & $(17)^{\complement}$ & $(39.9)^{d}$ & $(23.2)^{\mathrm{e}}$ & $(47.7)^{f}$ & $(27.9)^{\mathrm{g}}$ & \\
\hline \multirow[t]{2}{*}{$<6$ hours of night-time sleep ${ }^{3}$} & 599 & 553 & 678 & 787 & 678 & 717 & 4,012 & $<0.05$ \\
\hline & $(31.6)^{a}$ & $(37.9)^{b}$ & $(38.3)^{\mathrm{b}}$ & $(47.4)^{c}$ & $(49.6)^{c}$ & $(56)^{d}$ & $(42.5)^{\mathrm{e}}$ & \\
\hline \multirow[t]{2}{*}{$\geq 1$ hours of day-time sleep ${ }^{3}$} & 1450 & 1215 & 1519 & 1556 & 1244 & 1219 & 8203 & $<0.05$ \\
\hline & $(76.5)^{\mathrm{a}}$ & $(83.3)^{\text {be }}$ & $(85.8)^{\mathrm{b}}$ & $(93.7)^{\mathrm{cd}}$ & $(91)^{c}$ & $(95.2)^{d}$ & $(87.9)^{\mathrm{e}}$ & \\
\hline
\end{tabular}

Data are presented as either means and standard deviation for continuous variables; or $\mathrm{N}(\%)$ for categorical variables. Uncommon letters denote statistically significant differences abcdefg $(\mathrm{P}<0.05)$.

${ }^{1}$ Combination of dates, apples, oranges and bananas.

${ }^{2}$ Combination of carrots, salad and corn.

${ }^{3}$ P-values based on z-test for column proportions, adjusted by Bonferroni's correction for multiplicity.

percentage of boys achieved BMI scores $\geq 95^{\text {th }}$ percentile and waist-circumference scores $\geq 90^{\text {th }}$ percentile compared to girls. Increased prevalence of obesity amongst boys aged under 11 compared to girls was recently noted in a report based on National data from the Health Survey for England 2005 [44]. Within Saudi Arabia, boys aged 10-16 showed the largest increase in the prevalence of obesity in a study occurring between 1994 and 2000, whereas girls showed the smallest increase at ages 14-16 [45]. However other epidemiological studies in various areas of Saudi suggest that obesity is more prevalent in girls $[1,2]$. The reasons for this apparent dissimilarity are open to conjecture.

Our study indicated that the frequency of reported consumption of SSBC, added sugar in hot beverages, total sugar and number of local rice dishes increased with age in both male and female children, suggesting a trend towards sugar-rich foods and away from healthier food choices with advancing age. This was accompanied by a decrease in reported weekly consumption of milk (both full fat and low fat), fruit, vegetables, fish, eggs and cereal. These observations tend to confirm other studies which show that the quality of children's diets decrease over time [46] possibly due to a lessening of the parental influence [47] and increasing exposure to external influences and advertising. In the present study, self-reported consumption of SSCB and added sugars in hot beverages was significantly higher in boys aged 14-19 compared to girls of equal age, in keeping with previous observations in Saudi [48], the United States [49,50] and Great Britain [51]. The reason why boys tend to consume more soft drinks than girls is not fully understood, and should be explored further. SSCB consumption was positively correlated with larger W_C and BMI in Saudi boys, but not girls. Several [24-27] but not all [28-31] epidemiological studies have shown a link between sugar-sweetened soft drink consumption and obesity in children, and soft drink intake has also been associated with poor dietary choices [32,52], low protein and milk consumption [53]. We found that a high intake of SSCB correlated strongly with total sugar intake and total Kcal intake. One possible explanation for the association of SSCB intake and BMI, W_C could be that excessive sugars consumed may be stored as fat [54], leading to weight gain and increased adiposity. High sugar diets have also been shown to contribute to the development of Insulin Resistance and hyperlipidemia [55], components of the Metabolic Syndrome in which weight gain is a commonality. Our study also showed a positive association between SSCB intake and fast food meals, pizza, savory and sweet snack intake, and an inverse correlation with fruit, vegetable and milk intake. Fast food meals were also inversely correlated with fruit, vegetable and milk intake, in agreement with observations by French et al [56]. Conversely, full fat milk consumption correlates with more healthful dietary choices such as fruit, vegetable, eggs and cheese preferences, in both males and female Saudi children. Studies have shown that a greater intake of fruits and vegetables is associated with lower risk of overweight in children [57,58], and a recent cross-sectional analyses of the Third National Health and Nutrition Examination Survey (NHANES III) demonstrated an inverse association between central obesity and intake of fruits, vegetables and dairy products [59]. Several suggestions as to why increased vegetable and fruit intake might be protective against obesity include the notion that the replacement of high fat/energy-rich nutrients with relatively lower energy dense, water-rich vegetables and fruits might 


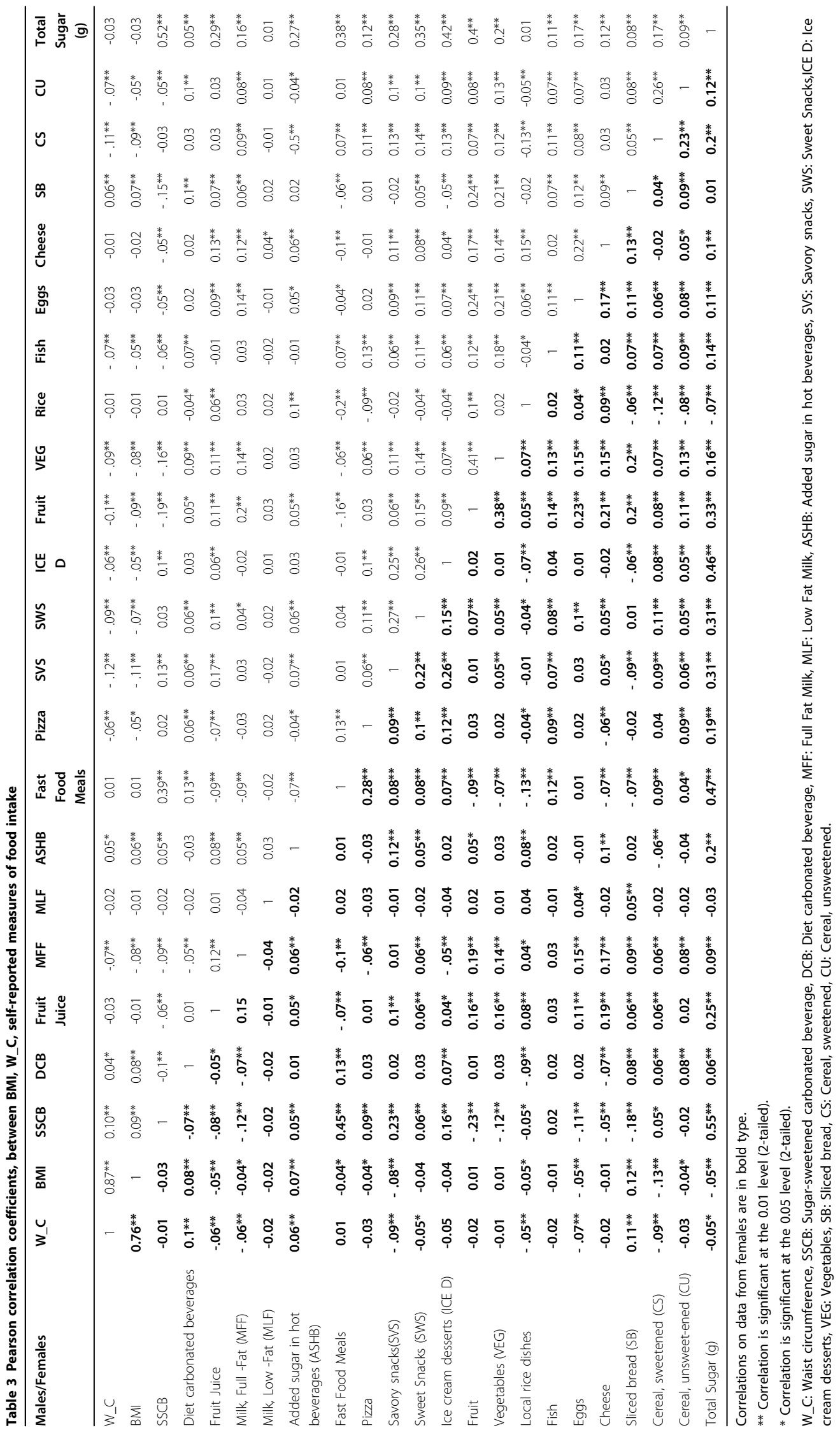


Table 4 Correlation coefficients between day/night-time sleep, exercise frequency, BMI, W_C and self-reported measures of food intake

\begin{tabular}{|c|c|c|c|c|c|c|c|c|c|c|}
\hline $\begin{array}{l}\text { Males/ } \\
\text { Females }\end{array}$ & $\begin{array}{c}\text { Waist } \\
\text { Circumference }\end{array}$ & BMI & SSCB & $\begin{array}{c}\text { Milk, } \\
\text { Full-Fat }\end{array}$ & Fruit & Vegetable & $\begin{array}{c}\text { Cereal, } \\
\text { unswee- } \\
\text { tened }\end{array}$ & $\begin{array}{c}\text { No. of } \\
\text { Exercise } \\
\text { Occasions }\end{array}$ & $\begin{array}{l}\text { Hours of } \\
\text { night-time } \\
\text { sleep }\end{array}$ & $\begin{array}{l}\text { Hours of day- } \\
\text { time sleep }\end{array}$ \\
\hline $\begin{array}{l}\text { Waist } \\
\text { Circumference }\end{array}$ & 1 & $.848^{* *}$ & $.106^{* *}$ & $-.075^{* *}$ & $-.092^{* *}$ & $-.092^{* *}$ & $-.083^{* *}$ & $-.179^{* *}$ & $-.086^{* *}$ & $.075^{* *}$ \\
\hline $\mathrm{BMI}$ & $.762^{* *}$ & 1 & $.085^{* *}$ & $-.079 * *$ & $-.077^{* *}$ & $-.078^{* *}$ & $-.045^{* *}$ & $-.148^{* *}$ & $-.078^{* *}$ & $.052^{* *}$ \\
\hline SSCB & -0.011 & -0.016 & 1 & $-.065^{* *}$ & $-.185^{* *}$ & $-.135^{* *}$ & $-.050 * *$ & -0.023 & -0.028 & $.148^{* *}$ \\
\hline Milk, Full-Fat & $-.054^{* *}$ & $-.054^{* *}$ & $-.108^{* *}$ & 1 & $.167^{* *}$ & $.130^{* *}$ & $.071^{* *}$ & $.119^{* *}$ & 0.008 & -0.028 \\
\hline Fruit & -0.009 & -0.008 & $-.235^{* *}$ & $.191 * *$ & 1 & $.398^{* *}$ & $.097^{* *}$ & $.182^{* *}$ & 0.024 & $-.083^{* *}$ \\
\hline Vegetables & -0.009 & -0.010 & $-.109 * *$ & $.107^{* *}$ & $.377^{* *}$ & 1 & $.146^{* *}$ & $.139 * *$ & 0.001 & $-.043^{* *}$ \\
\hline $\begin{array}{l}\text { Cereal, } \\
\text { unsweetened }\end{array}$ & -0.014 & $-.046^{* *}$ & -0.004 & $.074^{* *}$ & $.109 * *$ & $.113^{* *}$ & 1 & $.128^{* *}$ & -0.021 & 0.003 \\
\hline $\begin{array}{l}\text { No. of Exercise } \\
\text { Occasions }\end{array}$ & $.063^{* *}$ & $.071^{* *}$ & -0.033 & 0.018 & $.176^{* *}$ & $.161^{* *}$ & $.140 * *$ & 1 & -0.005 & 0.03 \\
\hline $\begin{array}{l}\text { Hours of } \\
\text { night-time } \\
\text { sleep }\end{array}$ & -0.030 & $-.053 * *$ & -0.013 & 0.013 & $.040^{*}$ & 0.011 & 0.029 & 0.019 & 1 & $-.035^{*}$ \\
\hline $\begin{array}{l}\text { Hours of day- } \\
\text { time sleep }\end{array}$ & $.036^{*}$ & $.063^{* *}$ & $.184^{* *}$ & $-.058^{* *}$ & $-.120^{* *}$ & $-.071 * *$ & $-.046^{* *}$ & $-.037^{*}$ & -0.009 & 1 \\
\hline
\end{tabular}

Correlations on data from females are in bold type.

** Correlation is significant at the 0.01 level (2-tailed).

* Correlation is significant at the 0.05 level (2-tailed).

Table 5 Correlates of $\mathrm{BMI}$ in a multivariate regression model. $¥$

\begin{tabular}{|c|c|c|c|c|}
\hline & \multirow[t]{2}{*}{ Standardized $\beta$} & \multirow[t]{2}{*}{ Sig. } & \multicolumn{2}{|c|}{ 95\% Confidence Interval for $\beta$} \\
\hline & & & Lower Bound & Upper Bound \\
\hline \multicolumn{5}{|l|}{ Males } \\
\hline SSCB & 0.10 & $<.0001$ & 0.09 & 0.17 \\
\hline DCB & 0.09 & $<.0001$ & 0.14 & 0.32 \\
\hline Sliced bread & 0.08 & $<.0001$ & 0.15 & 0.35 \\
\hline Added sugar in hot beverages & 0.05 & $<.01$ & 0.01 & 0.02 \\
\hline No. of exercise occasions & -0.18 & $<.0001$ & -0.77 & -0.53 \\
\hline Hours night-time sleep & -0.06 & $<.001$ & -0.27 & -0.08 \\
\hline Hours day-time sleep & 0.03 & 0.07 & -0.01 & 0.2 \\
\hline Adjusted $R^{2}$ & 0.06 & & & \\
\hline \multicolumn{5}{|l|}{ Females } \\
\hline DCB & 0.07 & $<.001$ & 0.09 & 0.27 \\
\hline Sliced bread & 0.11 & $<.0001$ & 0.21 & 0.41 \\
\hline Added sugar in hot beverages & 0.07 & $<.001$ & 0.01 & 0.03 \\
\hline Hours night-time sleep & -0.07 & $<.001$ & -0.22 & -0.06 \\
\hline Hours day-time sleep & 0.05 & $<.01$ & 0.03 & 0.21 \\
\hline Adjusted $R^{2}$ & 0.03 & & & \\
\hline
\end{tabular}

$¥$ See Table 1 and Table 2 for details of subjects and measurements.

reduce weight gain [60], and secondly that the higher fiber content of fruits and vegetables might blunt postprandial glycemic and insulinemic responses in the small intestine leading to a reduction in hunger and subsequent energy intake [61]. The inverse correlation of milk intake with SSCB consumption demonstrated in this and other studies is also a cause for concern, since a lower intake of milk may be associated with decreased bone density in children [62].
Our study indicated that fast food meals were consumed by Riyadh school children at an average of 4.5 times a week. This frequency contrasts markedly with data from the southwestern region of Saudi Arabia [2], in which a much smaller frequency of twice a month was reported for school children in the city of Abha. One reason for this difference in consumption may lie in the fact that Riyadh, with six times the urban population of Abha, is the capital city of Saudi Arabia, with an 
Table 6 Correlates of waist circumference in a multivariate regression model. $¥$

\begin{tabular}{|c|c|c|c|c|}
\hline & \multirow[t]{2}{*}{ Standardized $\beta$} & \multirow[t]{2}{*}{ Sig. } & \multicolumn{2}{|c|}{ 95\% Confidence Interval for $\beta$} \\
\hline & & & Lower Bound & Upper Bound \\
\hline \multicolumn{5}{|l|}{ Males } \\
\hline SSCB & 0.10 & $<.0001$ & 0.19 & 0.39 \\
\hline DCB & 0.06 & $<.001$ & 0.14 & 0.53 \\
\hline Sliced bread & 0.11 & $<.0001$ & 0.51 & 0.97 \\
\hline Added sugar in hot beverages & 0.04 & 0.03 & 0.01 & 0.04 \\
\hline Fruit & -0.05 & 0.01 & -0.16 & -0.02 \\
\hline Fish & -0.05 & 0.01 & -0.95 & -0.13 \\
\hline Vegetables & -0.04 & 0.03 & -0.27 & -0.02 \\
\hline Cereal, sweetened & -0.09 & $<.0001$ & -0.99 & -0.44 \\
\hline No. of exercise occasions & -0.18 & $<.0001$ & -1.76 & -1.22 \\
\hline Hours night-time sleep & -0.06 & $<.001$ & -0.62 & -0.19 \\
\hline Adjusted $R^{2}$ & 0.08 & & & \\
\hline \multicolumn{5}{|l|}{ Females } \\
\hline DCB & 0.09 & $<.0001$ & 0.27 & 0.61 \\
\hline Sliced bread & 0.12 & $<.0001$ & 0.42 & 0.79 \\
\hline Added sugar in hot beverages & 0.06 & $<.001$ & 0.02 & 0.06 \\
\hline Cereal, sweetened & -0.1 & $<.0001$ & -0.82 & -0.38 \\
\hline Milk, Full-Fat & -0.05 & $<0.01$ & -0.32 & -0.05 \\
\hline Eggs & -0.07 & $<.0001$ & -0.52 & -0.18 \\
\hline Adjusted $R^{2}$ & 0.04 & & & \\
\hline
\end{tabular}

$¥$ See Table 1 and Table 2 for details of subjects and measurements.

affluent infrastructure and approximately 35,000 fast food outlets [63]. It is also noteworthy that the overall prevalence of overweight and obesity in Riyadh is significantly higher than that of Abha [2].

The frequency of exercise occasions decreased with advancing age, and was inversely correlated with BMI and W_C in boys only, in keeping with previous observations [64]. Females were less likely to exercise, with up to $40 \%$ of girls performing no exercise at all, which may have important implications for the future, since a sedentary lifestyle is a major factor in all-cause mortality rates amongst adults [65].

The usual limitations of this cross-sectional study is that causal relationships between various types of food and beverage consumption and body measurements cannot be ascertained, but can only be used to generate hypotheses which may be evaluated by future prospective randomized trials if necessary. The present study is further limited by the accuracy of the self-reported dietary intake, a feature shared by many studies of this nature. The issue of reporting bias has recently been addressed by Savage et al [66], who concluded that plausible reporting of energy intake may predict BMI in preadolescent children. A simple analytical procedure was used to identify reporting bias, using a \pm 1 standard deviation cut-off for energy intake plausibility. This approach was also adopted by Ventura et al [42], whereas
Huang et al [41] found that biological plausibility was highest with energy intake cut-offs of between \pm 1 and $\pm 1.4 \mathrm{SD}$. In adopting a cut-off of $\pm 1 \mathrm{SD}$, we retained three quarters of our original study population for the correlative analysis, and thus the associations between SSCB and BMI in Saudi boys can be considered valid.

\section{Conclusions}

This study of 9433 school children points to an association between SSCB intake, W_C and BMI in boys age 10-19. Secondly, SSCB intake correlates with poor dietary choices such as fast food meals, savory snacks, and ice cream desserts in both males and females. Conversely, milk consumption was inversely correlated with BMI and W_C, and positively associated with fruit, vegetable, dates, eggs and cheese intake in both genders. SSCB and fast food meal intake may be important factors in evaluating the relationship between overall dietary intake and dietary choices, particularly in the adolescent population. Our data points to a need for further studies into the effect of dietary choices on the growing trend towards obesity.

\section{Abbreviations}

SSCB: sugar-sweetened carbonated beverage; DCB: Diet carbonated beverage; W_C: waist circumference; WHO: World Health organization; \%DV: percentage Daily Value; SD: standard deviation. 


\section{Acknowledgements}

This work was supported by King Faisal Specialist Hospital \& Research Centre, Research Advisory Council project \#2061 027

\section{Author details}

${ }^{1}$ Cell Biology \& Diabetes Research Unit, Department of Biological \& Medical Research, King Faisal Specialist Hospital \& Research Centre, PO BOX 3354, Riyadh 11211, Saudi Arabia. ${ }^{2}$ Biostatistics, Epidemiology \& Scientific Computing, King Faisal Specialist Hospital \& Research Centre, PO BOX 3354 Riyadh 11211, Saudi Arabia. ${ }^{3}$ Biochemistry Department, College of Science King Saud University Riyadh, KSA.

\section{Authors' contributions}

KSC conceived of the study and participated in its design, data analysis, interpretation, presentation and drafted the manuscript. MZZ participated in the data collection and analysis, and in the generation of figures and tables for the manuscript. SS participated in the data collection and analysis. MS oversaw statistical considerations and KA-R supervised data collection. FA-M participated in the study design, manuscript drafting and data analysis and interpretation. All authors read and approved the final manuscript.

\section{Competing interests}

The authors declare that they have no competing interests.

\section{Received: 14 July 2009 Accepted: 9 May 2010 Published: 9 May 2010}

\section{References}

1. El-Hazmi MA, Warsy AS: The prevalence of obesity and overweight in 1-18-year-old Saudi children. Ann Saudi Med 2002, , 5-6: 303-307.

2. Farghaly NF, Ghazali BM, Al-Wabel HM, Sadek AA, Abbag Fl: Life style and nutrition and their impact on health of Saudi school students in Abha, Southwestern region of Saudi Arabia. Saudi Med J 2007, 28(3):415-21.

3. Al-Hazzaa HM: Prevalence and trends in obesity among school boys in Central Saudi Arabia between 1988 and 2005. Saudi Med J 2007, 28(10):1569-74.

4. El Mouzan Ml, Al Herbish AS, Al Salloum AA, Foster PJ, Al Omar AA, Qurachi MM, Kecojevic T: Comparison of the 2005 growth charts for Saudi children and adolescents to the 2000 CDC growth charts. Ann Saudi Med 2008, 28(5):334-40,

5. Bray GA, Gray DS: Obesity. Part I-Pathogenesis. West J Med 1988, 149(4):429-441.

6. Bray GA, Jablonski KA, Fujimoto WY, Barrett-Connor E, Haffner S, Hanson RL, Hill JO, Hubbard V, Kriska A, Stamm E, Pi-Sunyer FX: Relation of central adiposity and body mass index to the development of diabetes in the Diabetes Prevention Program. Diabetes Prevention Program Research Group. Am J Clin Nutr 2008, 87(5):1212-8.

7. Fair AM, Montgomery K: Energy balance, physical activity, and cancer risk. Methods Mol Biol 2009, 472:57-88.

8. Dietz WH: Health consequences of obesity in youth: childhood predictors of adult disease. Pediatrics 1998, 101(3 Pt 2):518-25.

9. Lebovitz HE, Banerji MA: Point: visceral adiposity is causally related to insulin resistance. Diabetes Care 2005, 28(9):2322-2325

10. Hirschler V, Aranda C, Calcagno Mde L, Maccalini G, Jadzinsky M: Can waist circumference identify children with the Metabolic Syndeome? Arch Pediatr Adolesc Med 2005, 159(8):740-744.

11. Koster A, Leitzmann MF, Schatzkin A, Mouw T, Adams KF, van Eijk JT, Hollenbeck AR, Harris TB: Waist circumference and mortality. Am J Epidemiol 2008, 167(12):1465-75.

12. Reis JP, Araneta MR, Wingard DL, Macera CA, Lindsay SP, Marshall SJ: Overall obesity and abdominal adiposity as predictors of mortality in U.S. White and black adults. Ann Epidemiol 2009, 19(2):134-42.

13. Obesity: preventing and managing the global epidemic. Report of a WHO consultation. World Health Organ Tech Rep Ser 2000, 894:i-xii, 1-253.

14. Ogden CL, Yanovski SZ, Carroll MD, Flegal KM: The epidemiology of obesity. Gastroenterology 2007, 132:2087-102.

15. World Health Organization: Global database on body mass index. [http:// www.who.int/bmi/index.jsp?introPage=intro_3.html].

16. Must A, Jacques PF, Dallal GE, Bajema CJ, Dietz WH: Long-term morbidity and mortality of overweight adolescents. A follow-up of the Harvard Growth Study of 1922 to 1935. N Engl J Med 1992, 327(19):1350-5.
17. Al Mamun A, Cramb SM, O'Callaghan MJ, Williams GM, Najman JM: Childhood Overweight Status Predicts Diabetes at Age 21 Years: A Follow-up Study. Obesity (Silver Spring) 2009, 17(6):1255-61.

18. Singh AS, Mulder C, Twisk JW, van Mechelen W, Chinapaw MJ: Tracking of childhood overweight into adulthood: a systematic review of the literature. Obes Rev 2008, 9(5):474-88.

19. Warsy AS, el-Hazmi MA: Diabetes mellitus, hypertension and obesitycommon multifactorial disorders in Saudis. East Mediterr Health J 1999, 5(6): 1236-42.

20. Al-Othaimeen Al, Al-Nozha M, Osman AK: Obesity: an emerging problem in Saudi Arabia. Analysis of data from the National Nutrition Survey. East Mediterr Health J 2007, 13(2):441-8.

21. Block JP, DeSalvo KB, Fisher WP: Are physicians equipped to address the obesity epidemic? Knowledge and attitudes of internal medicine residents. Prev Med 2003, 36(6):669-75.

22. BMl calculations for children and teens. [http://www.cdc.gov/ healthyweight/assessing/bmi/childrens_bmi/about_childrens_bmi.html].

23. Brown CM, Dulloo AG, Montani JP: Sugary drinks in the pathogenesis of obesity and cardiovascular diseases. Int J Obes (Lond) 2008, 32(Suppl 6): S28-34.

24. Berkey CS, Rockett HR, Field AE, Gillman MW, Colditz GA: Sugar-added beverages and adolescent weight change. Obes Res 2004, 12:778-788.

25. Gillis $\perp$, Bar-Or O: Food away from home, sugar-sweetened drink consumption and juvenile obesity. J Am Coll Nutr 2003, 22:539-545.

26. Nicklas TA, Yang SJ, Baranowski T, Zakeri I, Berenson G: Eating patterns and obesity in children. The Bogalusa Heart Study. Am J Prev Med 2003, 25:9-16.

27. Ludwig DS, Peterson KE, Gortmaker SL: Relation between consumption of sugar-sweetened drinks and childhood obesity: a prospective, observational analysis. Lancet 2001, 357:505-508.

28. Forshee R, Storey M, Allison D, Glinsmann W, Hein G, Lineback D, Miller S, Nicklas $T$, Weaver $G$, White J: A critical examination of the evidence relating high fructose corn syrup and weight gain. Crit Rev Food Sci Nutr 2007, 47:561-82.

29. Andersen LF, Lillegaard IT, Overby N, Lytle L, Klepp Kl, Johansson L: Overweight and obesity among Norwegian schoolchildren: changes from 1993 to 2000. Scand J Public Health 2005, 33:99-106.

30. Bandini LG, Vu D, Must A, Cyr H, Goldberg A, Dietz WH: Comparison of high-calorie, low-nutrient-dense food consumption among obese and non-obese adolescents. Obes Res 1999, 7:438-443.

31. Gómez-Martínez S, Martín A, Romeo J, Castillo M, Mesena M, Baraza JC, Jiménez-Pavón D, Redondo C, Zamora S, Marcos A: Is soft drink consumption associated with body composition? A cross-sectional study in Spanish adolescents. Nutr Hosp 2009, 24(1):97-102.

32. Yamada M, Murakami K, Sasaki S, Takahashi Y, Okubo H: Soft drink intake is associated with diet quality even among young Japanese women with low soft drink intake. J Am Diet Assoc 2008, 108:1997-2004.

33. Hattersley L, Irwin M, King L, Allman-Farinelli M: Determinants and patterns of soft drink consumption in young adults: a qualitative analysis. Public Health Nutr 2009, 6:1-7.

34. Nielsen SJ, Popkin BM: Changes in beverage intake between 1977 and 2001. Am J Prev Med 2004, 27:205-210.

35. Wolff $E$, Dansinger ML: Soft drinks and weight gain: how strong is the link? Medscape J Med 2008, 10(8):189-198.

36. Dhingra R, Sullivan L, Jacques PF, Wang TJ, Fox CS, Meigs JB, D'Agostino RB, Gaziano JM, Vasan RS: Soft drink consumption and risk of developing cardiometabolic risk factors and the metabolic syndrome in middleaged adults in the community. Circulation 2007, 116(5):480-8.

37. Al-Nozha MM, Al-Maatouq MA, Al-Mazrou YY, Al-Harthi SS, Arafah MR, Khalii MZ, Khan NB, Al-Khadra A, Al-Marzouki K, Nouh MS, Abdullah M, Attas O, Al-Shahid MS, Al-Mobeireek A: Diabetes mellitus in Saudi Arabia. Saudi Med J 2004, 25:1603-1610.

38. Al-Nozha M, Al-Khadra A, Arafah MR, Al-Maatouq MA, Khalil MZ, Khan NB, Al-Mazrou YY, Al-Marzouki K, Al-Harthi SS, Abdullah M, Al-Shahid MS, AlMobeireek A, Nouh MS: Metabolic Syndrome in Saudi Arabia. Saudi Med J 2005, 26(12):1918-25.

39. Fernández JR, Redden DT, Pietrobelli A, Allison DB: Waist circumference percentiles in nationally representative samples of African-American, European-American, and Mexican-American children and adolescents. J Pediatr 2004, 145:439-44. 
40. U.S. Department of Agriculture, Agriculture Research Service. USDA National Nutrient database for Standard reference, Release 21. Nutrient data Laboratory Homepage 2007 [http://www.ars.usda.gov/nutrientdata].

41. Huang T-K, Roberts $S$, Howarth NC, McCrory MA: Effect of screening out implausible energy intake reports on relationship between diet and BMI. Obesity Research 2005, 13(7):1205-1217.

42. Ventura AK, Loken E, Mitchell DC, Smiciklas-Wright H, Birch LL: Understanding reporting bias in the dietary recall data of 11-year old girls. Obesity (Spiver Spring) 2006, 14(6):1073-1084.

43. Baranowski T, Mendlein J, Resnicow K, Frank E, Weber Cullen K, Baranowski JJ: Physical activity and nutrition in children and youth: an overview of obesity prevention. Prev Med 2000, 31:S1-S10.

44. Obesity among children under 11. 29 April 2005. Department of Health UK. [http://www.dh.gov.uk/en/Publicationsandstatistics/Publications/ PublicationsStatistics/DH_4109245].

45. Abalkhail B: Overweight and obesity among Saudi Arabian children and adolescents between 1994 and 2000. East mediterr Health J 2002, 8(4-5):470-479.

46. Lytle L, Seifert S, Greenstein J, McGovern P: How do children's eating patterns and food choices change over time?: Results from a cohort study. Am J Health Promot 2000, 14:222-228.

47. O'Dougherty M, Storey M, Lytle L: Food choices of young AfricanAmerican and Latino adolescents: where do parents fit in? J Am Diet Assoc 2006, 106(11):1846-50.

48. Bello LL, Al-Hammad N: Patterns of fluid consumption in a sample of Saudi Arabian adolescents aged 12-13. Int J Pediatr Dent 2006, 16(3):168-173.

49. French SA, Lin BH, Guthrie JF: National trends in soft drink consumption among children and adolescents age 6 to 17 years: prevalence, amounts, and sources, 1977/1978 to 1994/1998. J Am Diet Assoc 2003, 103(10):1326-31.

50. Jacobsen MF: Liquid Candy: how soft drinks are harming American's health. Washington DC: Centre for Science in the Public Interest. [http:// www.cspinet.org/new/pdf/liquid_candy_final_w_new_supplement.pdf].

51. He FJ, Marrero NM, MacGregor GA: Salt intake is related to soft drink consumption in children and adolescents: a link to obesity? Hypertension 2008, 51(3):629-34.

52. Rodríguez-Artalejo F, García EL, Gorgojo L, Garcés C, Royo MA, Martín Moreno JM, Benavente M, Macías A, De Oya M: Investigators of the Four Provinces Study. Consumption of bakery products, sweetened soft drinks and yogurt among children aged 6-7 years: association with nutrient intake and overall diet quality. Br J Nutr 2003, 89:419-429.

53. Vartanian LR, Schwartz MB, Brownell KD: Effects of soft drink consumption on nutrition and health: a systematic review and meta-analysis. $\mathrm{Am} J$ Public Health 2007, 97(4):667-75.

54. Minehira K, Bettschart V, Vidal H, Vega N, Di Vetta V, Rey V, Schneiter P, Tappy L: Effect of carbohydrate overfeeding on whole body and adipose tissue metabolism in humans. Obes Res 2003, 11(9):1096-103.

55. Basciano H, Federico-Adeli K: Fructose, insulin resistance, and metabolic dyslipidemia. Nutr Metab (Lond) 2005, 2(1):5.

56. French SA, Story M, Neumark-Sztainer D, Fulkerson JA, Hannan P: Fast food restaurant use among adolescents: associations with nutrient intake, food choices and behavioral and psychosocial variables. Int J Obes Relat Metab Disord 2001, 25(12):1823-33.

57. Lin $\mathrm{BH}$, Morrison RM: Higher fruit consumption linked with lower body mass index. Food Rev 2002, 25:28-32.

58. Epstein LH, Gordy CC, Rayner HA, Beddome M, Kilanowski CK, Paluch R: Increasing fruit and vegetable intake and decreasing fat and sugar intake in families at risk for childhood obesity. Obes Res 2001, 9:171-178.

59. Bradlee ML, Singer MR, Qureshi MM, Moore LL: Food group intake and central obesity among children and adolescents in the Third National Health and Nutrition Examination Survey (NHANES III). Public Health Nutr 2009, 22:1-9.

60. Ello-Martin JA, Roe LS, Ledikwe JH, Beach AM, Rolls BJ: Dietary energy density in the treatment of obesity: a year-long trial comparing 2 weight-loss diets. Am J Clin Nutr 2007, 85(6):1465-77.

61. Pereira MA, Ludwig DS: Dietary fiber and body-weight regulation. Pediatr Clin North Am 2001, 48:1-9.

62. Kalkwarf HJ, Khoury JC, Lanphear BP: Milk intake during childhood and adolescence, adult bone density, and osteoporotic fractures in US women. Am J Clin Nutr 2003, 77(1):257-65.
63. Riyadh municipality general Department of Environmental Health. [http://seha.alriyadh.gov.sa]

64. Hussey J, Bell C, Bennett K, O'Dwyer J, Gormley J: Relationship between the intensity of physical activity, inactivity, cardiorespiratory fitness and body composition in 7-10-year-old Dublin children. Br J Sports Med 2007, 41(5):311-6.

65. Katzmarzyk PT, Church TS, Craig CL, Bouchard C: Sitting Time and Mortality from All Causes, Cardiovascular Disease, and Cancer. Med Sci Sports Exerc 2009, 41(5):998-1005.

66. Savage JS, Mitchell DC, Smiciklas-Wright H, Downs DS, Birch L: Plausible reports of energy intake may predict body mass index in pre-adolescent girls. J am Diet Assoc 2008, 108:131-135.

\section{Pre-publication history}

The pre-publication history for this paper can be accessed here: http://www.biomedcentral.com/1471-2458/10/234/prepub

\section{doi:10.1186/1471-2458-10-234}

Cite this article as: Collison et al:: Sugar-sweetened carbonated beverage consumption correlates with BMI, waist circumference, and poor dietary choices in school children. BMC Public Health 2010 10:234.

\section{Submit your next manuscript to BioMed Central and take full advantage of:}

- Convenient online submission

- Thorough peer review

- No space constraints or color figure charges

- Immediate publication on acceptance

- Inclusion in PubMed, CAS, Scopus and Google Scholar

- Research which is freely available for redistribution

Submit your manuscript at www.biomedcentral.com/submit
Ciomed Central 